\title{
Aspectos Ecdóticos da Carta de Caminha
}

\section{Ecdotic Aspects of Caminha's Letter}

\section{Gladiston Alves da Silva}

Como citar esse artigo. da Silva, G.A. Aspectos Ecdóticos da Carta de Caminha. Revista Mosaico, v.11, n.2, p. $70-75,2020$.

Nota da Editora. Os artigos publicados na Revista Mosaico são de responsabilidade de seus autores. As informações neles contidas, bem como as opiniões emitidas, não representam pontos de vista da Universidade de Vassouras ou de suas Revistas.

\section{Resumo}

O presente trabalho busca apresentar alguns fundamentos da disciplina Crítica Textual no tratamento dos textos, principalmente textos antigos que passaram por diversas transformações e acabaram perdendo a sua originalidade. Desta feita, quando nos deparamos com a Carta de Caminha nos livros didáticos destinados aos alunos do ensino básico, verificamos que houve um tratamento em relação ao texto visando possibilitar ao aluno uma compreensão mais clara das informações passadas por Pero Vaz de Caminha ao Rei de Portugal; entretanto, essa maior clareza no texto significa uma adequação da língua falada em Portugal quinhentista com a língua falada atualmente. Em face disso, várias são as mudanças apresentadas no texto original que acabam mostrando a transformação da própria língua portuguesa, porém tais mudanças não são apontadas nos livros didáticos. Neste artigo, nos valemos de um fragmento da Carta original de Caminha arquivada na Torre do Tombo em Portugal e também da transcrição diplomática, da mesma forma arquivada na Torre do Tombo, bem como da transcrição crítica atualizada realizada pela Biblioteca Nacional do Brasil. Nesse estudo, destacamos as mudanças ocorridas no português a partir do Século XVI. Tais mudanças podem ser notadas no uso de vogais, de consoantes, nas construções com nasalidades, no uso de verbos. Verificamos também que a sintaxe da língua portuguesa se manteve estável, não sendo percebida nenhuma mudança nos fragmentos estudados. Também se manteve estável a manutenção de sujeito desinencial, assim como as concordâncias no interior da frase.

Palavras-chave: Carta de Caminha; Análise; Transcrição; Ecdótica.

\begin{abstract}
This research presents some foundations of the ecdotic discipline in relation to the texts, mainly old texts that underwent several transformations and lost their originality. The Letter of Pero Vaz de Caminha, which we see in the textbooks intended for students, has a treatment that aims to enable the student to acquire a clearer understanding of the information passed by that reporter to the King of Portugal. However, this greater clarity in the text means an adequacy of the language spoken in Portugal in the 16th century to the language spoken in Brazil in its contemporaneity. Owing to that, there are several changes from the original text showing the linguistic transformation. In this article, we draw on the original Caminha Letter and diplomatic transcript filed at Torre do Tombo in Portugal, as well as on the updated critical transcript by the Brazilian National Library. Only the beginning of the letter was analyzed, pointing out these changes to those interested in continuing this study. In this study, we highlight the changes that occurred in Portuguese from the 16th Century. Such changes can be noted in the use of vowels, consonants, constructions with nasalities, the use of verbs. We also verified that the syntax of the Portuguese language remained stable, not being noticed any change in the studied fragments. The maintenance of deinential subject was also stable, as well as the agreement within the sentence.

Keywords: Caminha's Letter; Transcription; Ecdotic.
\end{abstract}

\section{Introdução}

A Linguística e a Crítica Textual apesar de serem duas disciplinas independentes, estão intimamente relacionadas, muito embora esse fato não seja considerado na maior parte dos estudos sobre o tema. A crítica textual, na maioria dos estudos, está ligada diretamente à literatura, talvez por motivos óbvios desde o seu surgimento. Nesse sentido, o primeiro passo aqui, é traçar os pontos de contato mais destacados entre Linguística e Crítica Textual, onde se insere esse trabalho acadêmico.
Sabe-se que a Crítica Textual, como bem abordado por Cambraia (2005), é uma disciplina autônoma e que possui métodos próprios, reunindo em si a experiência de vários séculos e, por isso, pretende fixar um texto literário ou não, tal como saiu das mãos de seu autor, depurando as suas imperfeições e erros, bem como os sucessos que foram acumulados com a passagem do tempo. Assim, a Crítica Textual tem um escopo tão extenso quanto o dos textos em que trabalha, independentemente do idioma ou da escrita. Daí surgir a denominação de crítica textual clássica, crítica textual românica, crítica textual de obras de autores gregos ou 
latinos, e até de crítica textual de autores e obras que apresentam um problema específico, como a crítica textual de Homero, por exemplo.

A Crítica Textual nascida e desenvolvida na órbita da Filologia e das Escolas Helenísticas, conforme preconizam Spaggiari e Perugi (2004), continuará durante o período romano e durante os séculos IV, V e VI na Universidade de Constantinopla e em outras escolas do Império Bizantino. Porém esse trabalho será interrompido e seu desenvolvimento prejudicado por ocasião das invasões nórdicas no Ocidente e das invasões árabes no Oriente, bem como, talvez, pela influência dos clérigos mais interessados na mera transmissão das obras de conteúdo religioso do que no estudo dos clássicos.

Após um longo período, a Crítica Textual reaparece novamente no Primeiro Humanismo Bizantino, no século IX-X, e após as Cruzadas e os contatos comerciais e culturais entre a Itália e Bizâncio, será exportada de volta para o Ocidente, juntamente com as Universidades, uma criação bizantina, que a Itália irá implantar em todo o Ocidente durante o renascimento dos séculos XIII a XVI. É nesse momento que a Crítica Textual conhecerá métodos completamente novos: o emendatio ope codicum (estudo comparativo dos vários manuscritos disponíveis) e o emendatio ope ingenii (correção na base da conjectura, resultado da divinatio), isto é, a conjectura dessas passagens deterioradas durante o período dos séculos sombrios, e até o embelezamento dos textos do ponto de vista classicista.

O problema da escrita é um fator comum entre a Crítica Textual e a Linguística, por outro lado, é o primeiro ponto de contato entre elas. A escrita é talvez o procedimento mais importante para imobilizar e consertar a língua, tendo em vista que o próprio surgimento dela é um divisor de águas na História da humanidade e, assim, com seu desenvolvimento, veio cumprir muitas funções sociais, e, dentre elas, a de maior destaque é a política. A comunicação entre os povos e a evolução da economia, por exemplo, beneficiaram-se sobremaneira desse novo aspecto.

A escrita, seja ela qual for, sempre foi uma maneira de representar a memória coletiva religiosa, mágica, científica, política, artística e cultural. A invenção do livro e sobretudo da imprensa são grandes marcos da História da humanidade, depois é claro, da própria invenção da escrita. Esta foi passando do domínio de poucas pessoas para o do público em geral e seu consumo é mais significativo na forma de leitura do que na produção de textos. (CAGLIARI, 2010, p. 97)

A circulação de ideias apontada por Cagliari (2010) viabiliza-se como escrita enquanto modo de leitura. Esse aspecto favoreceu o florescimento e a manutenção das relações entre colônias e metrópoles que se estabeleceram desde o período medieval até os séculos recentes passados.
Nesse sentido, no que tange ao editor crítico textual, este deverá estabelecer um texto que deve preservar as ideias fomentadas pelo autor com todos os fenômenos gráficos que, devido às mudanças na redação, podem ter influenciado o nível de edição. É verdade que esse aspecto pertence antes à relação entre codicologia e linguística. Portanto, é necessário definir em que aspectos a crítica textual depende da codicologia e em quais outros ela deve desenvolver seus procedimentos em linguística, semântica ou estilística.

Para o editor de uma obra, o contexto será determinado pela consideração do trabalho literário do ponto de vista da crítica textual. No que diz respeito ao termo, o trabalho literário será a criação pessoal de um autor. Mas quanto ao ponto de partida, é o resultado de uma série de gerações e pessoas que, sem interrupção, intervieram diretamente no texto, tanto em seu conteúdo linguístico, semântico e estilístico, quanto no trabalho de mera transmissão e preservação do texto original e prováveis intervenções.

O texto de uma obra literária é, em primeiro lugar, um produto da tradição. Segundo, a obra literária é o resultado de uma tradição literária que geralmente a precedeu e é o produto de uma sociedade com certas características sociais e culturais, o que possibilitou a um determinado autor criar uma obra específica, com certas características. Ou seja, a obra literária é uma criação de seu autor e um produto da tradição.

É nesse sentido que este trabalho pretende analisar a primeira página de duas edições da carta de Pero Vaz de Caminha - considerada a certidão de nascimento do Brasil -, a primeira edição seria o original, em edição fac-similar, extraída do site oficial do Arquivo Nacional da Torre do Tombo (Portugal) e exemplifica o que Teyssier (1982) denomina português clássico e Bechara (2004) português médio ${ }^{1}$. A segunda edição está escrita em português contemporâneo e foi extraído do sítio da Biblioteca Nacional. Para fins deste artigo, utilizarse-ão as terminologias: português arcaico e português contemporâneo.

Em um primeiro momento, realizar-se-á a transcrição diplomática da Carta de Pero Vaz de Caminha, com base em dados extraídos do Arquivo Nacional da Torre do Tombo, bem como com uso da própria cópia da carta para que a transcrição seja fiel, linha a linha, posteriormente, far-se-á a transcrição crítica atualizada, em cotejo com a Carta original, na medida do possível.

Por fim, realizou-se a análise dos Registros Filológicos e dos Registros de variantes, para demonstrar as mudanças ocorridas na língua portuguesa através dos séculos, desde o "achamento" das terras brasileiras pelos navegadores europeus. Sendo necessário, porém, fazer algumas considerações sobre os aspectos básicos de Crítica Textual Ecdótica que fundamenta este trabalho. 


\section{Considerações teóricas}

$\mathrm{Na}$ área da Historiografia Linguística é de se observar que a Carta de Caminha pode ser vista como uma fonte de estudo não canônica. Entretanto, destacase que "tais fontes, também consideradas marginais, não raro contribuem para esclarecer aspectos ideológicos de dado autor [...], sobretudo em face das autoavaliações ou das críticas nelas presentes e ordinariamente ausentes nas fontes canônicas." (CAVALIERE, 2012, p. 366):

No ramo da Crítica Textual, é importante destacar os dizeres de Maximiano de Carvalho e Silva (1994, p. 57):

A Crítica Textual, com o seu método rigoroso de investigação histórico-cultural e genética, toma os textos como expressões da cultura pessoal ou social, com as preocupações fundamentais de averiguar a autenticidade dos mesmos e a fidedignidade da sua transmissão através do tempo, e de cuidar de interpretá-los, prepará-los e reproduzi-los em edições que se identifiquem ou se aproximem o mais possível da vontade dos autores ou dos testemunhos primitivos de que temos conhecimento.

Ainda no campo da Crítica Textual Ecdótica, Cambraia (2005, p. 1) vem enfatizar que "Um dado fundamental para compreender o escopo da crítica textual é o fato de que um texto sofre modificações ao longo do processo de sua transmissão." Nesse sentido, "seu objetivo primordial é a restituição da forma genuína dos textos". Entretanto, no que diz respeito ao termo Ecdótica, então, notadamente, "o termo abarca não apenas a restituição da forma genuína de um texto, mas também os procedimentos técnicos para apresentar o texto ao público".

Outro dado importante a ser enfrentado é o aspecto filológico desse estudo, pois a Filologia é uma ciência linguística de ampla atuação e que estuda a língua em todos os seus aspectos através dos textos. A língua vem sendo estudada há muito tempo, entretanto só a partir do século XIX, com o surgimento da Filologia propriamente dito, é que há a necessidade de se tornar científico os estudos linguísticos, surgindo, a partir de então, novos métodos que visavam explicar os fenômenos linguísticos envolvidos na literatura. A Filologia não pode ser confundida com a Crítica Textual como tentaram fazer, no passado, alguns teóricos, pois enquanto a Crítica Textual busca recuperar o sentido do texto do seu autor, sempre com base nas edições surgidas ao longo do tempo, a filologia busca explicar a língua através dos escritos.

$\mathrm{Na}$ ótica da Linguística, a língua é vista como o estudo da linguagem e a linguagem é a leitura do pensamento, não se concebendo um sem o outro. Logo, ela é o próprio elemento de comunicação social, pois não há sociedade sem linguagem ou sem comunicação. A língua como parte social da linguagem, é constituída através de signos que se combinam de acordo com leis específicas. Se a fala é individual, a língua é social, e, para que a fala se socialize, é necessário obedecer a regras sociais de acordo com os códigos estabelecidos.

Nesse sentido, é que se direciona esse estudo, buscando recuperar uma carta do passado distante, ou seja, do início de uma futura literatura brasileira, para averiguar o comportamento da língua em diversos aspectos, entre eles podemos destacar: a) o objetivo específico de Pero Vaz de Caminha em comunicar à Coroa Portuguesa a nova do descobrimento com os aspectos de seu código próprio; b) verificar as mudanças linguísticas surgidas com o passar do tempo; c) avaliar as consequências dessa mudança e projetar novas mudanças no interior da língua.

Sendo assim, para uma melhor compreensão do trabalho, é importante destacar alguns conceitos na área de Crítica Textual extraídos e adaptados a partir de Cambraia (2005) e Spaggiari e Perugi (2004):

- Edição Fac-similar: baseia-se no grau zero de mediação, pois apenas se reproduz a imagem de um testemunho através de meios mecânicos, como fotografia, xerografia, escanerização etc.

- Edição Diplomática: forma de mediação bastante limitada, com baixo grau de mediação. Nesta edição, faz-se uma transcrição rigorosamente conservadora de todos os elementos presentes no modelo, dispensando o leitor da árdua tarefa de decifrar as formas gráficas da escrita original.

- Transcrição Diplomática: na transcrição Diplomática, é necessário manter a divisão em linhas em conformidade com o manuscrito.

- Edição Crítica: caracteriza-se pelo confronto de mais de um testemunho, sendo, essa edição, o objeto da Crítica Textual, pois é nessa edição que se faz a devida atualização da ortografia e pontuação e, por isso, possui alto grau de mediação.

- Registro Filológico: estabelece as regras de ortografia atualizadas no momento da edição.

- Registro das Variantes: estabelece as mudanças textuais, como troca, inclusão e exclusão de palavras e pontuação.

\section{Parte da primeira página da Carta de Caminha}

Como dito anteriormente, nosso foco é a carta de Caminha, porém seria impossível nesse espaço dar conta de tanto trabalho, tendo em vista o tamanho da carta e o volume de informações envolvido nesse documento. Desta feita, optou-se por dar início a esse estudo, firmando o terreno para que outros interessados no tema possam dar continuidade a essa tarefa. Nesse aspecto, abaixo apresenta-se uma cópia de parte da primeira página da Carta para que se possa desenvolver nossa análise a partir dela. 


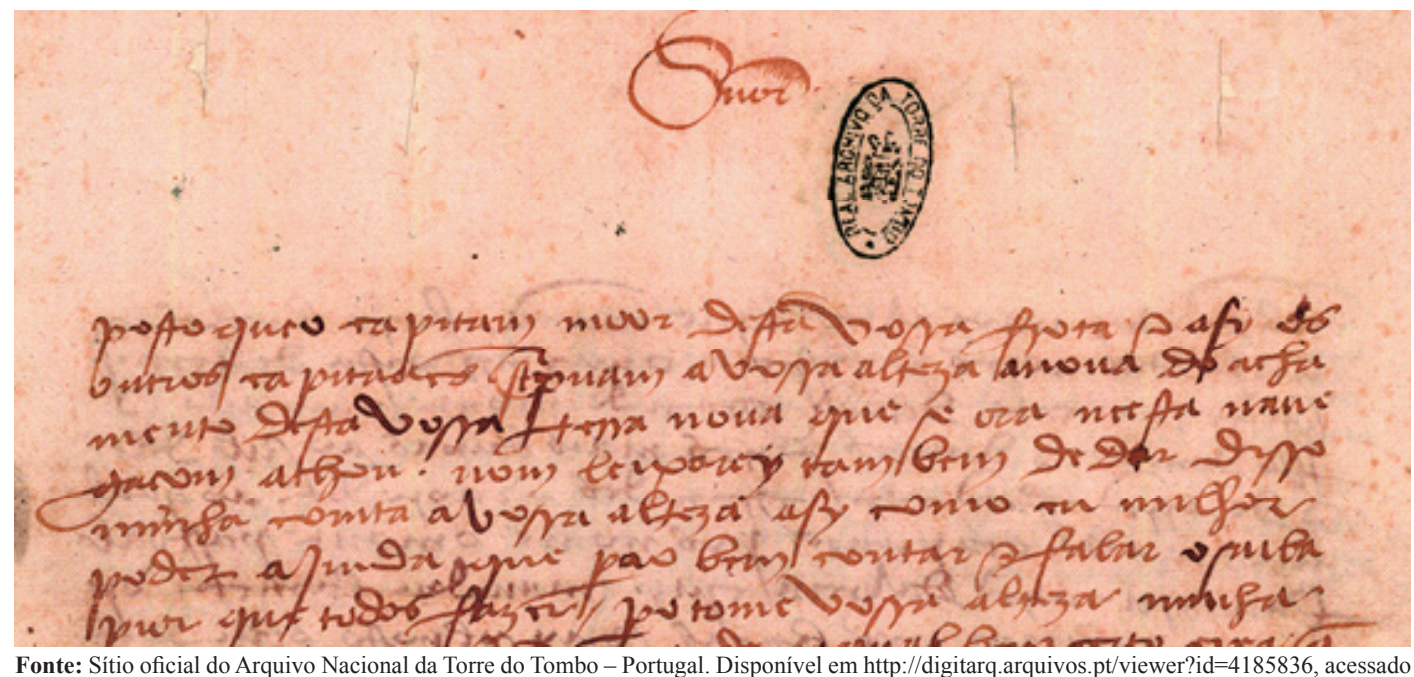

Fonte: Sítio oficial do Arquivo Nacional da Torre do Tombo - Portugal. Disponível em http://digitarq.arquivos.pt/viewer?id=4185836, acessado em $04 / 11 / 2017$

\section{Transcrição diplomática da Carta de Pero Vaz de Caminha}

Snõr

posto que o capitam moor desta vossa frota e asy os outros capitaães screpuam a vossa alteza a noua do acha

Linha 5 mento desta vossa terra noua que se ora neesta naue gaçom achou, nom leixarey tambem de dar disso minha comta a vossa alteza asy como eu milhor poder ajmda que pera o bem contar e falar o saiba pior que todos fazer,

\section{Transcrição crítica atualizada da Carta de Pero Vaz de Caminha Registro Filológico}

Senhor:

Posto que o Capitão-mor desta vossa frota, e assim os outros capitães escrevam a Vossa Alteza a nova do acha-

Linha 5 mento desta vossa terra nova, que ora nesta navegação se achou, não deixarei também de dar disso minha conta a Vossa Alteza, assim como eu melhor puder, ainda que - para o bem contar e falar — o saiba pior que todos fazer. 
1) Desdobramento de escrita: Snõr/Senhor;

2) Regularização do uso de 'ss': asy/assim;

3) Regularização do uso do 'm' nasal: assim

4) Regularização do uso da maiúscula: Posto, Capitãomor, Vossa, Alteza

5) Regularização de ditongo nasal: Capitão, navegação, não

6) Substituição do u/v: escrevam, nova, navegação

7) Eliminação de vogal dupla: mor, capitães, nesta

8) Acréscimo da vogal 'e' antes do 's': escrevam

9) Eliminação de consoante muda: escrevam

10) Substituição do $1 /$ d: deixarei

11) Substituição do y/i: deixarei

12) Substituição do $j / i$ : ainda

13) Substituição do $\mathrm{m} / \mathrm{n}$ : conta, ainda

14) Substituição do i/e: melhor

15) Substituição do o/u: puder

16) Substituição de preposição: pera/para

17) Regularização de acentuação: também

\section{Registro de Variantes}

LINHA 1: Inclusão de ( : ) após 'Senhor'.

LINHA 2: Inclusão de ( - ) na composição de 'Capitãomor'; Inclusão de (, ) depois de 'frota'.

LINHA 3: Inclusão de ( - ) na separação de 'achamento'.

LINHA 4: Inclusão de (, ) depois de 'nova'; Inclusão de ( - ) na separa de 'navegação'; Exclusão da partícula "se" antes de ora.

LINHA 5: Inclusão da partícula 'se' antes de 'achou'.

LINHA 6: Inclusão de (, ) depois de 'Alteza'.

LINHA 7: Inclusão de (, ) depois de 'puder'; Inclusão de ( - ) ante de 'para' e depois de 'falar'.

LINHA 8: Substituição da (, ) por ( . ) depois de 'fazer'.

\section{Considerações Finais}

Como é possível notar, grande parte das palavras utilizadas neste pequeno fragmento da Carta de Pero Vaz de Caminha guardam bastante semelhança com a forma escrita da nossa língua atualmente, não havendo dificuldade em reconhecer sua representação ortográfica da época. Vejamos: posto que o capitam moor desta vossa frota e asy os - posto que o capitão-mor desta vossa frota e assim os - este trecho demonstra a estabilidade da ortografia e da própria língua. A exceção, talvez, de asy, que pode criar um primeiro estranhamento, todas as demais palavras são perfeitamente compreensíveis e algumas, inclusive, permaneceram inalteradas, como frota, desta e vossa, por exemplo. As que mudaram, mudaram muito pouco, como é caso de capitam que teve a ortografia alterada com a retirada do ' $\mathrm{m}$ ' final e o acréscimo de 'o' com o sinal gráfico 'til' no 'a'.

Verificamos também, que já no início do Século XVI, as palavras apresentavam uma segmentação, cuja marca na escrita é o espaço em branco. Tal espaço em branco corresponde à segmentação tradicional das palavras na língua. Lembremos que em textos bem anteriores a essa época, o português escrito não fazia a separação de palavras, ficando inclusive, hoje, difícil de fazer uma leitura mais dinâmica. Outro fator importante a apontar é que nesse pequeno retalho aparece palavra ajuntada, por exemplo, encontramos o artigo definido singular ' $a$ ' juntando-se à palavra seguinte no caso de anoua (a nova).

Também, nesse trecho, notamos uma ocorrência interessante da vogal 'i' quando esta era substituída por ' $y$ ' quando estava localizada em uma sílaba tônica ou nasalizada, por exemplo: aymda (ainda), asy (assim), leixarey (deixarei), o que pode representar que diante de consoante nasal, que ocorre imediatamente antes de uma consoante oclusiva, a letra ' $i$ ', provavelmente, tinha uma qualidade nasalizada. Nesse pequeno levantamento de ocorrências de vogais em posição de núcleo silábico, as vogais 'a', 'e' e 'o' ocorreram nos três contextos: inicial (asy, outros), medial (achamento, desta, frota) e final (vossa, disso, que), porém, a vogal 'i' não aparece em início e final de palavras, sendo substituído por ' $y$ ', como em asy.

Há uma grande variedade de ditongos decrescentes na Carta de Caminha, neste trecho encontramos alguns, por exemplo: saiba, leixarey. Também verificamos a existência de vogais duplicadas e alguns autores argumentam que essa característica significava um prolongamento da sílaba ou uma tonicidade, como por exemplo, em: capitaães e neesta.

Outro fato interessante e que pode ser destacado é a grafia de milhor (melhor). Note-se que havia certa confusão em palavras desse tipo, uma vez que para os falantes do português arcaico o 'i' e 'e' representavam o mesmo som, assim como 'o' e 'u'. Por essa razão, acredita-se que o fato de se escrever milhor, não represente que se falasse dessa forma, ocorrendo, talvez o que ocorre hoje em relação a essas mesmas vogais em finais de palavras.

No que se refere às consoantes, destaca-se a letra 'l' que já aparecia formando dígrafo 'lh': milhor. Também é de se destacar a representação escrita da nasalidade na Carta, tendo em vista que a nasalidade é representada ortograficamente pelas consoantes ' $\mathrm{m}$ ' e 'n', pelo dígrafo 'nh' e pelo til. Em início de sílabas: milhor, minha. É interessante notar uma aleatoriedade do uso de ' $m$ ' e ' $n$ ' quando a nasalidade se encontrava dentro da palavra escrita sem separação por espaço em branco ou por outra marca, como se verifica nos exemplos a seguir: comta, contar, ajmda e também. 
Palavras que não são verbos, separadas por espaço em branco, apresentam a letra ' $m$ ' na coda final: capitam, nauevagaçom. Da mesma forma, a terminação da terceira pessoa plural dos verbos apresenta a consoante ' $m$ ', quando seguidos de espaço em branco: screpuam. É de se observar também o uso do dígrafo 'nh' na época de Caminha, como em: minha.

Como é possível notar, o português escrito por Pero Vaz de Caminha na época do 'achamento' mudou consideravelmente nesses mais de cinco séculos. As mudanças que ocorreram foram de todas as ordens e envolvendo as variadas classes de palavras, entretanto a sintaxe sofreu poucas alterações, tanto assim, que no fragmento apontado não encontramos nenhuma mudança sintática. As orações são constituídas por sujeitos, verbos e objetos. Por exemplo, no período: os outros capitaães screpuam a vossa alteza - Encontramos o sujeito: 'Os outros capitães'; o verbo: 'escrevam'; e o objeto: ‘a vossa alteza'. Não havendo qualquer observação em relação e essa construção, ainda hoje.

Também é de se destacar que há a presença de sujeitos ocultos ou elípticos ou desinenciais, como ainda hoje encontramos na nossa língua escrita e falada, como por exemplo, em: nom leixarey tambem de dar. Nesse caso, o sujeito é desinencial, 'eu'. As concordâncias seguem a mesma estrutura da língua, permanecendo praticamente inalterada até onde pode ser visto nesta análise. Tal fato reflete o que as teorias linguísticas apontam em relação às mudanças da sintaxe, ou seja, todas as línguas mudam naturalmente com o passar do tempo, entretanto a sintaxe da língua muda muito mais lentamente. Essa estabilidade na sintaxe da língua portuguesa pode ser explicada em razão da publicação, ainda no Século XVI, em 1536, da primeira gramática da língua portuguesa, escrita por Fernão de Oliveira.

$\mathrm{O}$ estudo das antigas obras nos ajuda a entender as mudanças, não só da língua, mas principalmente da nossa sociedade, nos fazendo refletir sobre o caminho que queremos traçar para o nosso futuro e para $\mathrm{o}$ futuro da própria humanidade. A carta que se encontra guardada na Torre do Tombo, em Lisboa, pode e deve servir para o ensino de base, pois a história que envolve o descobrimento está registrada nesse elemento escrito em que o seu autor transmite suas informações em uma oralidade da época.

O professor deve propor uma discussão sobre esse tema e, o ponto de partida, pode ser justamente os aspectos levantados por esta pesquisa, tendo em vista que os dados que são informados aqui, são apenas iniciais e, assim, são propositadamente, para que seja possível dar continuidade, seguindo um caminho já definido. As crianças e adolescentes, ao mesmo tempo em que discutem a formação do Brasil podem reconhecer as mudanças linguísticas ocorridas nesse período, pois todo vestígio existente do passado deve servir de ferramenta para avançar no conhecimento da história.
A Carta de Pero Vaz de Caminha é uma fonte de valor legal, devendo ser reconhecida como um verdadeiro documento histórico, como de fato já é. Nesse aspecto, pretende-se aproximar os alunos e professores dos procedimentos de trabalho de um linguista, filólogo ou crítico textual, ou mesmo um historiador. O espaço é amplo e pode ser ocupado por todos. Cada um na sua área, contribuindo para o desenvolvimento das ciências envolvidas.

\section{Nota}

1. Para fins deste trabalho, utilizar-se-á o termo 'português arcaico'.

\section{Referências}

BORGES, Rosa; SOUZA, Arivaldo Sacramento de. Filologia e edição de texto. In: BORGES, Rosa et al. Edição de textos e crítica filológica. Salvador: Quarteto, 2012. p. 15-59.

CAGLIARI, Luiz Carlos. Alfabetização e linguística. 10. ed. São Paulo: Scipione, 2001.

CAMBRAIA, César Nardelli. Introdução à crítica textual. São Paulo: Martins Fontes, 2005.

CAMINHA, Pero Vaz de. Carta ao Rei Dom Manuel. Minas Gerais: Crisálida, 2002.

CAMINHA. Pero Vaz de. A carta de Pero Vaz de Caminha. Acervo digital da Biblioteca Nacional. Disponível em: ttp://objdigital.bn.br/Acervo_Digital/ livros eletronicos/carta.pdf. Acesso em: 04 nov. 2017.

CARVALHO e SILVA, Maximiano. Crítica textual: conceito - objeto finalidade. Confluência, Rio de Janeiro, n. 7, p. 57-63, 1. sem. 1994.

CAVALIERE, Ricardo. As fontes orais e sua relevância nos estudos linguísticos-historiográficos. 2012. Disponível em: http://www.scielo.br/pdf/ delta/v29n2/08.pdf. Acesso em: 12 nov. 2017

MATOS E SILVA, Rosa Virgínia. Nos territórios da língua (Linguística Histórica e Filologia hoje: redefinindo fronteiras). In: III Encontro de Ecdótica e Crítica Genética. João Pessoa, 1993.

SPAGGIARI, Bárbara; PERUGI, Maurizio. Fundamentos da Crítica Textual Rio de Janeiro: Lucerna, 2004. 